\title{
Literatur Review : Analisis Pengolahan Data Sensus Harian Rawat Inap di Rumah Sakit
}

\section{Literature Review : Analysis of Data Processing of Inpatient Daily Census in Hospital}

\author{
Fauziah Nur Arfiah ${ }^{1}$, Trismianto Asmo Sutrisno ${ }^{2, *}$ \\ ${ }^{1}$ Prodi D3 RMIK STIKes Mitra Husada Karanganyar \\ ${ }^{2}$ Prodi Sarjana Terapan MIK STIKes Mitra Husada Karanganyar \\ Jl.Brigjen Katamso Barat, Gapura Papahan Indah, Papahan, Tasikmadu, Karanganyar, Jawa Tengah \\ *e-mail korespondensi: trismianto@stikesmhk.ac.id
}

\begin{abstract}
Abstrak
Rumah Sakit wajib melakukan pencatatan dan pelaporan tentang semua kegiatan penyelenggaraan Rumah Sakit. Pencatatan dan pelaporan diambil dari data sensus harian rawat inap. Dalam pengolahan sensus harian rawat inap masih dijumpai ketidakakuratan data sehingga tidak dapat dimanfaatkan secara maksimal. Tujuan penelitian ini untuk mengetahui proses pengolahan data sensus harian rawat inap. Metode yang digunakan adalah literature review dengan strategi pencarian menggunakan Google Scholar dengan kata kunci Sensus Harian Rawat Inap dan Rumah Sakit. Hasil penelitian ini adalah kegiatan pengolahan data Sensus Harian Rawat Inap (SHRI) diterima petugas analising reporting untuk dilakukan perekapan yang dilaksanakan secara komputerisasi dengan menginput data pada komputer dan manual dalam bentuk tabel. Sensus dilaksanakan mulai pukul 00.00 WIB selama 24 jam. Namun, masih dijumpai ketidakakuratan data sehingga data tidak dapat dimanfaatkan secara maksimal dan mengakibatkan penilaian kinerja pelayanan di rumah sakit tidak efisien. Maka perlu dilakukannya pembaharuan SOP agar petugas bangsal/ruang dapat melakukan pembuatan SHRI dengan benar sehingga data yang dihasilkan lebih akurat. Dalam pembuatan, penyerahan, perekapan SHRI sebaiknya dilakukan setiap hari agar mendapat data yang up to date dan real time, sehingga data yang dihasilkan lengkap, akurat dan tersedia saat diperlukan untuk dimanfaatkan dalam perhitungan pelayanan indikator rawat inap.
\end{abstract}

Kata kunci: Pengolahan Data, Sensus Harian Rawat Inap

\begin{abstract}
Hospitals are required to record and report all activities of the Hospital administration. Recording and reporting are taken from daily inpatient census data. In processing the daily census of inpatients, data inaccuracies are still found so that it cannot be utilized optimally. The purpose of this study was to determine the daily census data processing process for inpatients. The method used is literature review with a search strategy using Google Scholar with the keywords Daily Census Inpatient and Hospital. The result of this research is that daily inpatient census data processing activities are received by theofficer analyzing reporting for recapitulation which is carried out computerized by inputting data on a computer and manually in table form. The census was held starting at $00.00 \mathrm{WIB}$ for 24 hours. However, data inaccuracies were still found so that the data could not be utilized optimally and resulted in inefficient assessment of service performance in hospitals. So it is necessary to update the SOP so that ward / room officers can make SHRI properly so that the resulting data is more accurate. In making, submitting, SHRI registration should be carried out every day in order to obtain up to date and real timedata, so that the resulting data is complete, accurate and available when needed to be used in calculating inpatient indicator services.
\end{abstract}

Keywords: Data Processing, Daily Inpatient Census

p-ISSN: | e-ISSN: 2807-2596

website: ijhim.stikesmhk.ac.id/index.php/ 


\section{PENDAHULUAN}

Rumah Sakit wajib melakukan pencatatan dan pelaporan tentang semua kegiatan penyelenggaraan Rumah Sakit dalam bentuk Sistem Informasi Manajemen Rumah Sakit (SIMRS) (Undang-Undang No 44, 2009). Pencatatan ini merupakan salah satu bentuk tertib administrasi rumah sakit dalam hal membuat dan memelihara rekam medis.

Pencatatan merupakan awal dari pembuatan laporan yang dimulai dari tempat penerimaan pasien atau Tempat Pendaftaran Pasien (TPP) hingga pasien mendapatkan pelayanan kemudian pasien pulang. Dalam melakukan pencatatan maka dibutuhkan datadata untuk dikumpulkan. Aktivitas yang rutin dilaksanakan di rumah sakit yang secara langsung menghitung jumlah pasien yang dilayani di unit rawat inap, dengan perhitungan jumlah pasien yang masih ada di unit tersebut juga dihitung jumlah pasien yang masuk dan keluar pada hari yang sama dengan hari pelaksanaan sensus disebut sensus harian rawat inap (Sudra, 2017).

Sensus harian rawat inap digunakan untuk mengontrol jumlah pasien yang masuk melalui tempat penerimaan pasien, mengontrol jumlah pasien pulang dari ruangan, mengontrol jumlah pasien yang dipindahkan keluar masuk antar ruangan, mengontrol jumlah pasien lahir atau meninggal, dan sebagai sumber data untuk sistem pelaporan (Budi, 2011).

Masalah yang sering muncul dalam pengolahan sensus harian rawat inap adalah masih sering dijumpai data rekapitulasi sensus harian yang salah, perhitungan indikator pelayanan rumah sakit yang tidak dilaporkan setiap bulan (Fitriya et al., 2018). Berdasarkan latar belakang tersebut peneliti tertarik mengambil judul "Literature Review : Analisis Pengolahan Data Sensus Harian Rawat Inap di Rumah Sakit”.

\section{METODE PENELITIAN}

Penelitian ini menggunakan desain literature review yaitu penelitian yang menelaah, membandingkan dan mengambil kesimpulan artikel penelitian tentang pengolahan data sensus harian rawat inap di rumah sakit untuk mengintegrasikan dan menarik kesimpulan.

Strategi pencarian literatur dalam literature review ini menggunakan database google scholar dengan keyword dan boolean operator "Sensus Harian Rawat Inap" AND "Rumah Sakit". Kriteria Inklusi yang digunakan yaitu artikel penelitian yang dipublikasikan tahun 2010-2020, indikator yang digunakan adalah pengolahan data sensus harian rawat inap, penelitian yang dilakukan dengan metode deskriptif, bahasa yang digunakan adalah Indonesia dan English. Sedangkan kriteria eksklusi yang digunakan yaitu penelitian tidak sama dengan tujuan, metode tidak tercantum dengan jelas, artikel hanya menampilkan abstrak atau tidak full text, artikel tidak bisa didownload. Seleksi artikel sebanyak 692 data hasil pencarian terseleksi sebanyak 8 dan 6 diantaranya dimasukkan dalam studi literature review. Ekstraksi data merupakan kegiatan meringkas informasi penting yang ditemukan pada setiap artikel penelitian yang ditinjau. Informasi ini digunakan untuk menjawab pertanyaan penelitian. Sintesis adalah kegiatan merangkum berbagai pengertian atau pendapat dari dua atau banyak bacaan untuk dihasilkan tulisan yang baru sesuai dengan kebutuhan penulis.

\section{HASIL DAN PEMBAHASAN}

HASIL

Tabel 1. Hasil Ekstraksi Data

\begin{tabular}{|c|c|c|c|c|}
\hline $\begin{array}{l}\text { Author } \\
\text { (Tahun) }\end{array}$ & $\begin{array}{c}\text { Nama Jurnal, } \\
\text { Volume, No }\end{array}$ & Judul & Metode & Outcome atau Hasil \\
\hline $\begin{array}{l}\text { Agung } \\
\text { Kurniawan, Tri } \\
\text { Lestari, }\end{array}$ & $\begin{array}{l}\text { Jurnal Kesehatan, } \\
\text { Vol. IV, } \\
\text { No. } 2\end{array}$ & $\begin{array}{l}\text { Analisis } \\
\text { Pemanfaatan Data } \\
\text { Sensus Harian } \\
\end{array}$ & Deskriptif & $\begin{array}{l}\text { a. Pengolahan data SHRI untuk } \\
\text { pelaporan indikator pelayanan } \\
\text { rawat inap diperoleh dari setiap }\end{array}$ \\
\hline
\end{tabular}


Rohmadi

(2010)
Rawat Inap Untuk

Pelaporan Indikator

Pelayanan Rawat

Inap di Rumah Sakit

Umum Daerah Dr.

Soeroto Ngawi bangsal perawatan dilanjutkan dengan rekapitulasi ke dalam formulir Rekapitulasi Harian Pasien Rawat Inap (RP.1) dan dijadikan sebagai dasar pembuatan indikator pelayanan rawat inap.

b. Faktor tidak terlaksananya SHRI dengan benar dikarenakan:

1) Tidak disiplinnya pengisian, penyerahan SHRI

2) Tidak adanya prosedur tetap dan petunjuk teknis pengisian SHRI.

Igustin
Budiyanti
Yusuf, Tri
Lestari,
Harjanti (2013)

Jurnal Kesehatan,

Vol. VII,

No. 2

Lestari,

Harjanti (2013)

Tinjauan
Pelaksanaan Sensus
Harian Rawat Inap
di Rumah Sakit
Umum Daerah
Pandan Arang
Boyolali Tahun 2013

Tinjauan

Boyolali Tahun 2013
Deskriptif a. Pengolahan sensus harian rawat inap dibuat oleh perawat ruangan kemudian membuat resume dan didapatkan data untuk penghitungan indikator rawat inap yaitu, BOR, LOS, TOI dan BTO.

b. Waktu perhitungan batas pembuatan SHRI dimulai pukul 00.01 hingga pukul 24.00 WIB.

\begin{tabular}{llll}
\hline Deasy & Jurkessia, & Tinjauan Keakuratan & Deskriptif \\
Rosmala Dewi, & Vol. IV, & Data Pada Sensus & \\
Gussa Azizah, & No. 3 & Harian Rawat Inap & \\
Retno Juwita & & di Rumah Sakit \\
$(2014)$ & & Khusus Bedah \\
& Banjarmasin Siaga
\end{tabular}
menjadi satu di kantor perawatan. a. Pengolahan sensus harian rawat inap pencatatan dilakukan pada masing-masing ruang perawatan. Memilah menurut jenis ruang perawatan kemudian digabung Dari rekapitulasi sensus harian rawat inap didapatkan laporan BOR, LOS, TOI, BTO, NDR, dan GDR.

b. Faktor tidak terlaksananya SHRI dengan benar karena kurangnya komunikasi dan pengetahuan perawat.

\begin{tabular}{lll}
\hline Elise Garmelia, & Jurnal Rekam & Tinjauan \\
Sri Lestari, & Medis dan & Pelaksanaan Sensus \\
Sudiyono, & Informasi & Harian Rawat Inap \\
Cory Puspa & Kesehatan, & di Rumah Sakit \\
Sari Dewi & Vol. 1, & Umum Daerah Kota \\
$(2018)$ & No. 1 & Salatiga
\end{tabular}

Deskriptif

a. Pengolahan sensus harian rawat Inap SIMRS dengan cek kelengkapan DRM kemudian update status pasien di SIMRS.

b. Waktu pelaksanaan SHRI secara SIMRS dilaksanakan lebih dari 24 jam.

c. Faktor tidak terlaksananya SHRI dengan benar yaitu :
1) Man (Human Resource) = pengetahuan \& pendidikan perawat bangsal
2) Money (Financial) = ketiadaan dana intensif
3) Machine (Information) = sensus tidak dilaksanakan sesuai SOP.




\begin{tabular}{llll}
\hline Hiskia & Jurnal Delima & Tinjauan Manfaat & Deskriptif \\
Yanuarius & Harapan, & Data Sensus Harian & \\
Numberi & Vol. 7, No. 2 & Rawat Inap di \\
$(2020)$ & & Rumah Sakit Umum \\
& & Muhammadiyah \\
& & Kabupaten Ponorogo
\end{tabular}
a. Pengolahan data sensus harian rawat inap untuk pelaporan diperoleh dari setiap bangsal perawatan setelah itu dilanjutkan dengan rekapitulasi ke dalam indikator kinerja rumah sakit dan dijadikan sebagai dasar pembuatan Indikator Pelayanan Rawat Inap (BOR, LOS, BTO, TOI, AvLOS, NDR dan GDR).
b. Faktor tidak terlaksananya SHRI dengan benar karena tidak disiplinnya pengisian dan penyerahan SHRI karena tidak ada prosedur tetap dan petunjuk teknis pengisian yang memuat seluruh kegiatan yang harus dilakukan oleh petugas bangsal rawat inap.

\begin{tabular}{llll}
\hline Ferly, & Jurnal Rekam & Analisis Pelaksanaan & Deskriptif \\
Rossalina Adi & Medik dan & Sensus Harian & \\
Wijayanti, & Informasi & Rawat Inap di & \\
Novita Nuraini & Kesehatan (J- & RSUD Dr. Saiful & \\
$(2020)$ & REMI), & Anwar Malang & \\
& Vol. 1, No. 4 & &
\end{tabular} Faktor tidak terlaksananya SHRI dengan benar yaitu :
a. Man (Human Resource) = pengetahuan dan pendidikan perawat bangsal
b. Money (Financial) = ketiadaan anggaran pelatihan dan sosialisasi pengisian SHRI
c. Methods (Legittimate) = SOP tentang pelaksanaan SHRI masih belum direvisi.

\section{PEMBAHASAN \\ Proses Pengolahan Sensus Harian Rawat Inap untuk Pelaporan}

Data yang terkumpul baik dari unit kerja lain (poliklinik ataupun bangsal) atau yang direkapitulasi oleh petugas MIK, selanjutnya diolah menjadi data yang terekap dan terangkum untuk diproses pada tahap lebih lanjut agar menghasilkan suatu informasi yang berguna bagi para pengambil keputusan (Sudra, 2017). Pada penelitian (Kurniawan et al., 2010; Yusuf et al., 2013; Dewi et al., 2014; Numberi, 2020; Garmelia et al., 2018) didapatkan persamaan dan perbedaan proses pengolahan SHRI untuk pelaporan dimana secara keseluruhan proses pengolahan SHRI melalui beberapa tahapan.

$$
\text { Pengolahan SHRI berdasarkan }
$$

(Kurniawan et al., 2010) dan (Numberi, 2020) yaitu hasil kegiatan data Sensus Harian Rawat Inap (SHRI) dari ruang keperawatan diterima petugas analising reporting untuk dilakukan perekapan setelah itu dilakukan pengolahan data sesuai kebutuhan pembuatan indikator pelayanan rawat inap. Sama halnya dengan (Dewi et al., 2014) yang menjelaskan bahwa pengolahan SHRI meliputi beberapa kegiatan seperti pencatatan sensus harian yang dilakukan pada masing-masing ruang perawatan dicatat dalam formulir sensus harian rawat inap, memilah sensus harian rawat inap menurut ruang perawatan kemudian digabung menjadi satu di kantor perawatan. Selanjutnya akan diambil oleh petugas rekam medis untuk diolah sebagai bahan pembuatan laporan indikator rawat inap.

Didukung dengan (Yusuf et al., 2013) yang menjelaskan bahwa sensus harian diisi lengkap oleh masing-masing petugas ruangan bangsal, disetorkan ke satuan rekam medis pengolahan data setiap pagi dan di tandatangani oleh kepala ruang, dilakukan cheking mengenai pasien yang keluar dan yang masuk, dilakukan proses rekapitulasi harian rawat inap dan 
disusun perbulan. Rekapitulasi bulanan dikumpulkan untuk bahan pelaporan kegiatan rumah sakit, dilakukan pengarsipan lembarlembar sensus harian rawat inap di satuan rekam medis. Hal ini telah sesuai dengan (Fitriya et al., 2018) yang menjelaskan bahwa pengolahan SHRI dilakukan dengan merekap data SHRI yang diterima untuk mengetahui data yang dibutuhkan dalam menghitung indikator pelayanan rumah sakit. Didukung dengan (Kementerian Kesehatan RI, 2011) yang menjelaskan bahwa pembuatan indikator pelayanan rawat inap bersumber dari sensus harian yang diperoleh dari ruang rawat inap berdasarkan formulir sensus harian yang direkapitulasi setiap bulan. Laporan diolah oleh bagian pengolah data sehingga laporan tersebut sesuai dengan kebutuhan untuk mengisi Rekapitulasi Laporan (RL) dan laporan rumah sakit. Adapun Rekapitulasi Laporan (RL) yang bersumber dari Sensus Harian Rawat Inap di antaranya:

a. RL 1.2 (Indikator Pelayanan Rumah Sakit)

b. RL 3 (Kegiatan Pelayanan Rumah Sakit)

c. RL 5.1 (Pengunjung Rumah Sakit)

d. RL 5.2 (Kunjungan Rawat Jalan)

Laporan rumah sakit terdiri dari laporan internal dan laporan eksternal.

a. Laporan Internal

Laporan internal yaitu pelaporan yang dibuat sebagai masukan untuk menyusun konsep rancangan dasar sistem informasi manajemen rumah sakit. Adapun laporannya meliputi:

1) Indikator Rawat Jalan

2) Indikator Gawat Darurat

3) Indikator Rawat Inap

4) Indikator Pelayanan Intensif

5) Indikator Kebidanan

6) Indikator Pelayanan Persalinan

7) Indikator Perinatologi

8) Indikator Pelayanan Rujukan

9) Indikator Pelayanan Operasi

10) Indikator Radiologi

11) Indikator Laboratorium

12) Indikator Farmasi

13) Indikator Sumber Daya Manusia

14) Indikator Proses dan Pelayanan Mutu

15) Indikator Financial

16) Indikator Kepuasan Pelanggan Eksternal b. Laporan Eksternal

Laporan eksternal yaitu laporan yang wajib dibuat oleh rumah sakit sesuai dengan peraturan yang berlaku, ditujukan kepada Departemen Kesehatan RI, Dinas Kesehatan Provinsi RI, Dinas Kesehatan Kabupaten/Kota. Adapun laporannya sebagai berikut:

1) Data identitas rumah sakit

2) Data ketenagaan yang bekerja di rumah sakit

3) Data rekapitulasi kegiatan pelayanan

4) Data kompilasi penyakit/ morbiditas pasien rawat inap

5) Data kompilasi penyakit/ morbiditas pasien rawat jalan

(Kementerian Kesehatan RI, 2011)

Berbeda dengan (Garmelia et al., 2018) pengolahan SHRI dilakukan secara SIMRS yaitu dengan cek kelengkapan rekam medis dan jaminan pasien, apabila tidak lengkap maka akan dikembalikan ke unit pengirim, namun jika sudah lengkap akan dilakukan update pada SIMRS.

Hal ini dapat disimpulkan bahwa proses pengolahan sensus harian rawat inap untuk pelaporan dimulai dari pengisian dan pencatatan oleh masingmasing ruang perawatan, yang selanjutnya direkap dalam formulir rekapitulasi rawat inap, kemudian dikumpulkan atau diambil oleh bagian pelaporan rekam medis (analising reporting) untuk diolah dijadikan dasar pembuatan laporan indikator pelayanan rumah sakit

\section{Waktu Pelaksanaan Sensus Harian Rawat Inap}

Periode sensus harian rawat inap adalah pukul 00.00 sampai dengan 24.00 (DepKes, 2005). Hal ini memiliki persamaan dengan (Yusuf et al., 2013) yang menyatakan bahwa sensus harian rawat inap di buat satu lembar saat malam hari oleh perawat yang jaga malam. Batasan pasien masuk mulai pukul 00.01 hingga pukul 24.00, setelah lewat jam 24.00 WIB maka dihitung hari berikutnya.

Didukung dengan (Yunita, et.al., 2012) dan (Lestari et al., 2020) yang menjelaskan 
bahwa pelaksanan pengisian sensus harian rawat inap dilakukan pukul 00.00 sampai dengan 24.00. Kegiatan SHRI ini dengan merekap data pasien masuk, keluar, pindah atau dipindahkan serta pasien meninggal dalam waktu 00.00 sampai dengan 24.00. Meskipun begitu berbeda dengan (Garmelia et al., 2018) yang menyebutkan bahwa terdapat perbedaan waktu pelaksanaan SHRI secara SIMRS yaitu dilakukan lebih dari 24 jam karena petugas tidak dilakukan update data sensus secara rutin.

Berdasarkan uraian di atas dapat disimpulkan bahwa pelaksanaan SHRI dilaksanakan selama 24 jam di mulai pukul 00.00 WIB. Waktu pelaksanaan sensus harian rawat inap tersebut juga telah sesuai dengan (Sudra, 2017) yang menjelaskan bahwa sensus umumnya dilaksanakan sekitar tengah malam (menjelang jam 24.00). Kebiasaan penetapan jam pelaksanaaan sensus harian menjelang tengah malam ini memiliki beberapa keuntungan, misalnya:

a. Suasana umumnya lebih tenang, tidak banyak pengunjung/keluarga pasien dan petugas lain

b. Suasana umunya lebih nyaman, tidak panas seperti pada siang hari

c. Suasana umumnya lebih santai, tidak sedang sibuk seperti pada jam kerja

d. Periode sensus akan lebih identik dengan periode waktu 24 jam dalam pengertian hari, tidak memenggal hari

(Sudra, 2017)

\section{Faktor Tidak Terlaksananya Sensus Harian Rawat Inap dengan Benar}

Terdapat persamaan faktor tidak terlaksananya SHRI dengan benar berdasarkan (Kurniawan et al., 2010) dan (Numberi, 2020) yaitu karena tidak disiplinnya pengisian dan penyerahan Sensus Harian Rawat Inap (SHRI) karena tidak adanya prosedur tetap dan petunjuk teknis yang memuat seluruh kegiatan yang harus dilakukan oleh petugas bangsal rawat inap. Hal ini menyebabkan isi dari sensus harian tidak sesuai dengan keadaan sebenarnya sehingga pemanfaatan data sensus harian tidak dilakukan secara maksimal.

Adapun faktor lainnya berdasarkan Garmelia et al. (2018) dan Ferly et al. (2020) yaitu :

a. Man (Human Resource)

Faktor Man (Human Resource) dalam hal ini berkaitan dengan pendidikan dan pengetahuan petugas bangsal. Pendidikan pengisi sensus yaitu dilaksanakan oleh admin bangsal dengan lulusan S1 atau D3 keperawatan (Garmelia et al., 2018; Ferly et.al., 2020). Pengetahuan dalam hal ini yaitu pengetahuan petugas sensus harian ruang rawat inap terkait dengan pengisian sensus harian rawat inap pada lembar formulir sensus dan penginputan pada microsoft excel (Ferly et.al., 2020).

b. Money (Financial)

Faktor yang mendasari tidak terlaksananya SHRI dengan benar salah satunya pada faktor money (financial). Dalam hal ini uang merupakan salah satu unsur yang tidak dapat diabaikan. Uang merupakan alat tukar dan alat pengukur nilai. Besar-kecilnya hasil kegiatan dapat diukur dengan jumlah uang yang beredar dalam perusahaan. Oleh karena itu uang merupakan alat (tools) yang penting untuk mencapai tujuan karena segala sesuatu harus diperhitungkan secara rasional. Hal ini akan berhubungan dengan berapa uang yang harus disediakan untuk membiayai gaji tenaga kerja, alat-alat yang dibutuhkan dan harus dibeli serta berapa hasil yang akan dicapai dari suatu organisasi (Hasibuan, 2013).

Hal ini berbeda dengan (Garmelia et al., 2018) yang menjelaskan bahwa pelaksanaan sensus tidak memiliki dana khusus atau insenstif bagi pihak yang melaksanakannya dikarenakan sensus merupakan kegiatan pokok yang harus dilakukan di unit rawat inap. Sedangkan (Ferly et.al., 2020) menjelaskan bahwa petugas sensus harian ruang rawat inap belum pernah mengikuti ataupun mengadakan pelatihan tentang sensus harian rawat inap. Hal tersebut dikarenakan pengajuan pelatihan membutuhkan dana sehingga dengan ketiadaan anggaran terkait pelatihan menjadi salah satu penyebab tidak terlaksananya kegiatan sensus harian rawat inap dengan benar. Pelatihan kerja diselenggarakan dan diarahkan untuk membekali, meningkatkan dan mengembangkan kompetensi kerja guna meningkatkan kemampuan, produktivitas dan kesejahteraan (Undang-Undang Republik Indonesia No. 13, 2003).

Berbeda dengan (Dewi et al., 2014) yang menjelaskan bahwa hasil indikator di rumah sakit tidak ideal karena berasal dari tidak adanya buku register rawat inap, sensus harian 
yang sudah tidak benar dalampengisiannya yang dilakukan perawat karena kurangnya komunikasi dan pengetahuan dalam mengisi data sensus harian, mengakibatkan terdapat selisih atau perbedaan jumlah pasien sisa dengan pasien awal. Ditambah dengan (Garmelia et al., 2018) yang menambahkan pada faktor Mechine (Information) yaitu sensus tidak dilaksanakan sesuai SOP yang telah disepakati di rumah sakit karna menggunakan SIMRS petugas tidak melaksanakan update data sensus secara rutin. Hal ini belum sesuai dengan (Kementerian Kesehatan RI, 2011) yang menjelaskan bahwa data yang baik adalah data yang bersifat terbarukan.

Faktor lain dari (Ferly et.al., 2020) yang menambahkan terkait faktor Methode (Legittimate) yaitu SOP tentang pelaksanaan SHRI masih belum direvisi. SOP petugas sensus harian rawat inap menjelaskan terkait penggunaan prosedur sensus harian rawat inap yang ada di seksi rekam medik dan ruangan menggunakan biling sistem yang ada di rumah sakit akan tetapi pada pelaksanaannya sensus harian masih menggunakan cara manual yaitu dengan mengisi pada formulir sensus harian rawat inap dan kemudian memasukkannya pada lembar kerja microsoft excel.

Hal ini sejalan dengan (Pelu, 2013) yang menjelaskan bahwa kegiatan pengelolaan sensus harian rawat inap dipengaruhi oleh beberapa faktor. Faktor-faktor yang berhubungan dengan keakuratan sensus harian rawat inap yaitu pengisian sensus harian rawat inap yang tidak lengkap, karakteristik petugas, dan prosedur tetap yang belum ditaati dan dijalankan oleh perawat. Ketepatan dalam mengisi sensus harian rawat inap oleh perawat bangsal akan mempengaruhi ketepatan perhitungan sensus harian rawat inap. Apabila perhitungan sensus harian rawat inap tidak tepat maka data performance rumah sakit yang dihasilkan tidak akurat, seperti data BOR, LOS, TOI, BTO, NDR, dan GDR.

Sesuai dengan (Kementerian Kesehatan RI, 2011) yang menjelaskan bahwa laporan indikator digunakan untuk menilai rumah sakit. Indikator efisiensi tersebut idealnya adalah :

a. Bed Occupancy Rate (BOR) $=60-85 \%$

b. Average Length Of Stay (AvLOS) $=6-9$ hari

c. Bed Turn Over $(\mathrm{BTO})=40-50$ kali dalam satu tahun d. $\quad$ Turn Over Interval $(\mathrm{TOI})=1-3$ hari

e. $\quad$ Net Death Rate $(\mathrm{NDR})=25$ per 1000

f. Gross Death Rate (GDR) $=45$ per 1000 penderita keluar

Dari uraian di atas sehingga dapat disimpulkan bahwa faktor tidak terlaksananya sensus harian rawat inap dengan benar yaitu :

a. Tidak disiplinnya pengisian dan penyerahan SHRI

b. Tidak adanya prosedur tetap dan petunjuk teknis pengisian SHRI

c. Kurangnya komunikasi antar perawat

d. Pendidikan dan pengetahuan perawat bangsal

e. Ketiadaan anggaran intensif, pelatihan dan sosialisasi pengisian SHRI

f. SOP yang belum direvisi dan tidak dilaksanakan dengan baik

\section{SIMPULAN}

Pengolahan Sensus Harian Rawat Inap Untuk Pelaporan. Hasil kegiatan data Sensus Harian Rawat Inap (SHRI) diterima petugas analising reporting untuk dilakukan perekapan setelah itu dilakukan pengolahan data sesuai kebutuhan pembuatan indikator pelayanan rawat inap. Waktu Pelaksanaan Sensus Harian Rawat Inap dimulai jam 00.00 WIB dilakukan selama 24 jam. Faktor Tidak Terlaksananya Sensus Harian Rawat Inap dengan Benar. Tidak disiplinnya pengisian dan penyerahan SHRI. Tidak adanya prosedur tetap dan petunjuk teknis pengisian SHRI. Kurangnya komunikasi antar perawat. Pendidikan dan pengetahuan perawat bangsal. Ketiadaan anggaran intensif, pelatihan dan sosialisasi pengisian SHRI. SOP yang belum direvisi dan tidak dilaksanakan dengan baik

\section{DAFTAR PUSTAKA}

Budi. (2011). Manajemen Unit Kerja Rekam Medis. Yogyakarta: Quantum Sinergis Media.

Catur Pamungkas Dewi Yunita, Cahya Tri Punami, Y. D. (2012). Evaluasi Kegiatan Manajemen Data Sensus Harian Rawat Inap Rumah Sakit Umum Daerah Banyumas Tahun 2011. JURNAL KESEHATAN MASYARAKAT, 1(1). 
Dewi, D. R., Azizah, G., Juwita, R., \& Borneo, S. H. (2014). Tinjauan Keakuratan Data pada Sensus Harian Rawat Inap Di Rumah Sakit Khusus Bedah Banjarmasin Siaga. Jurnal Kesehatan Indonesia, 4(3), 33-37. http://journal.stikeshb.ac.id/index.php/jurk essia/article/view/40

Elise Garmelia, S. L. S., Dewi, C. P. S., \& Jurusan. (2018). Tinjauan Pelaksanaan Kegiatan Sensus Harian Rawat Inap Di Rumah Sakit Umum Daerah Kota Salatiga. Jurnal Rekam Medis dan Informasi Kesehatan, 1(1), 27-36. http://ejournal.poltekkes-

smg.ac.id/ojs/index.php/RMIK/article/view 13592

Ferly, Rossalina Adi Wijayanti, N. N. (2020). Analisis Pelaksanaan Sensus Harian Rawat Inap Di RSUD DR. Saiful Anawar Malang. Jurnal Rekam Medik Dan Informasi Kesehatan, 1(4), 575-581. https://publikasi.polije.ac.id/index.php/jremi/article/view/2163

Fitriya, D., Yusuff, H., P, B. A., Studi, P., Medis, R., \& Cirebon, S. M. (2018). Tinjauan Pengolahan Sensus Harian Rawat Inap Di Unit Kerja Rekam Medis Rumah Sakit Umum Daerah Waled Kabupaten Cirebon. Kesehatan.

Hasibuan, S.P. (2013). Manajemen Sumber Daya Manusia. Jakarta:PT. Bumi Aksara.

Igustin Budiyanti Yusuf, Tri Lestari, H. (2013). Tinjauan Pelaksanaan Sensus Harian Rawat Inap Di Rumah Sakit Umum Daerah Pandan Arang Boyolali Tahun 2013. Kesehatan, $\quad 1, \quad 9-18$. https://ejurnal.stikesmhk.ac.id/index.php/r $\mathrm{m} /$ article/view/10/8

Kementerian Kesehatan RI. (2011). Juknis SIRS 2011: Sistem Informasi Rumah Sakit. In Direktorat Jenderal Bina Upaya Kesehatan (hal. 1-48).

Kurniawan, A., Lestari, T., \& Rohmadi. (2010). Analisis Pemanfaatan Data Sensus Harian Rawat Inap Untuk Pelaporan Indikator
Pelayanan Rawat Inap Di Rumah Sakit Umum Daerah Dr. Soeroto Ngawi. Kesehatan, IV(2), 62-86. https://ejurnal.stikesmhk.ac.id/index.php/r $\mathrm{m} /$ article/view/10/8

Lestari, D. F. A., Wicaksono, A. P., \& Deharja, A. (2020). Tinjau Faktor Ketidaktepatan Waktu Pengembalian Sensus Harian Rawat Inap di RSUP DR. Soeradji Tirtonegoro Tahun 2020. Rekam Medik Dan Informasi Kesehatan, 1(3), 374-380.

Numberi, H. Y. (2020). Tinjauan Pemanfaatan Data Sensus Harian Rawat Inap Di Rumah Sakit Umum Muhammadiyah Kabupaten Ponorogo. Jurnal Delima Harapan, 7(2), 73-85.

https://doi.org/10.31935/delima.v7i2.98

Pelu, N. I. F. D. (2013). Faktor- Faktor yang Berhubungan dengan Keakuratan Sensus Harian Rawat Inap Manual dan Elektronik Di RSIA Gunung Sawo Semarang Tahun 2012. In Universitas Dian Nuswantoro Semarang (Vol. 53, Nomor 9). /citations?view_op=view_citation\&continu $\mathrm{e}=/$ scholar\%3Fhl\%3Dpt-

BR\%26as_sdt\%3D0,5\%26scilib\%3D1\&cit ilm=1\&citation_for_view $=$ wSOxi2wAAA $\mathrm{AJ}: 20 s \mathrm{OgNQ} 5 \mathrm{qMEC} \& \mathrm{hl}=\mathrm{pt}-\mathrm{BR} \& \mathrm{oi}=\mathrm{p}$

Sudra, R.I. (2017). Rekam Medis. Ed. 2.Tangerang Selatan: Universitas Terbuka.

Undang-Undang Republik Indonesia No. 13 Tahun 2003. (2003). Undang-Undang Republik Indonesia No.13 Tahun 2003 tentang Ketenagakerjaan. Undang-Undang, 1 , 1-34. http://www.kemenperin.go.id/kompetensi/ UU_13_2003.pdf

Undang-Undang Republik Indonesia No. 44 Tahun 2009. (2009). Undang-Undang Republik INDONESIA Nomor 44 TAHUN 2009 Tentang Rumah Sakit (Nomor April). 